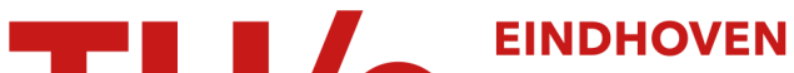 \\ UNIVERSITY OF \\ TECHNOLOGY
}

\section{Orthogonal strategy based computer-mediated negotiation}

Citation for published version (APA):

Susetyo, C., Timmermans, H. J. P., \& de Vries, B. (2019). Orthogonal strategy based computer-mediated negotiation: principles and example. Environment and Planning B: Urban Analytics and City Science, 46(6), 1036-1060. https://doi.org/10.1177/2399808317748160

DOI:

$10.1177 / 2399808317748160$

Document status and date:

Published: 01/07/2019

\section{Document Version:}

Accepted manuscript including changes made at the peer-review stage

\section{Please check the document version of this publication:}

- A submitted manuscript is the version of the article upon submission and before peer-review. There can be important differences between the submitted version and the official published version of record. People interested in the research are advised to contact the author for the final version of the publication, or visit the $\mathrm{DOI}$ to the publisher's website.

- The final author version and the galley proof are versions of the publication after peer review.

- The final published version features the final layout of the paper including the volume, issue and page numbers.

Link to publication

\section{General rights}

Copyright and moral rights for the publications made accessible in the public portal are retained by the authors and/or other copyright owners and it is a condition of accessing publications that users recognise and abide by the legal requirements associated with these rights.

- Users may download and print one copy of any publication from the public portal for the purpose of private study or research.

- You may not further distribute the material or use it for any profit-making activity or commercial gain

- You may freely distribute the URL identifying the publication in the public portal.

If the publication is distributed under the terms of Article $25 \mathrm{fa}$ of the Dutch Copyright Act, indicated by the "Taverne" license above, please follow below link for the End User Agreement:

www.tue.nl/taverne

Take down policy

If you believe that this document breaches copyright please contact us at:

openaccess@tue.nl

providing details and we will investigate your claim. 


\title{
Orthogonal Strategy Based Computer-Mediated Negotiation: Principles and Example
}

\author{
Cahyono Susetyo* \\ Department of Urban and Regional Planning, Institut Teknologi Sepuluh Nopember, \\ Gedung PWK - Kampus ITS, 60111 Surabaya, Indonesia \\ email: cahyono_s@urplan.its.ac.id, fax: (+62)315922425 \\ *corresponding author \\ Harry Timmermans, Bauke de Vries \\ Department of Built Environment, Eindhoven University of Technology, \\ Vertigo Building, 5600 MB Eindhoven, The Netherlands \\ email: h.j.p.timmermans@tue.nl,b.d.vries@tue.nl
}

\begin{abstract}
Previous efforts to improve stakeholders' involvement in planning and decision-making processes mostly put planners and decision-makers as the ones who decide which solution is the best for the decision problems. In bottom-up planning and decision-making processes that supposedly involve stakeholders as much as possible, the most common practice is that when stakeholders have different preferences about the decision issues, supra decision makers such as planners and experts gather stakeholders' preferences, and then, using their expertise and experience, decide what is the best choice for stakeholders. We approach the involvement of stakeholders in planning and decision-making not by relying on planners' expertise, but from a negotiation perspective.

Previous works related to stakeholders' negotiation mostly requires stakeholders to engage in a face-to-face negotiation that seldom involves a computer system to improve the process. In this paper, we develop a negotiation system to support multi-issue and multi-stakeholder decision-making problems. In our approach, stakeholders do not directly interact with each other. Their proposals are submitted to a system that produces counter-proposals to reduce the differences among stakeholders' proposals. Therefore, stakeholders do not exchange their preferences directly, but rather preference elicitations are mediated by the system. This approach is called ComputerMediated Negotiation. The system itself is based on the principle of an Orthogonal Strategy.

Our computer-mediated negotiation protocol consists of two main phases. The first phase is the Preference Elicitation phase, which measures stakeholders' utility functions. The second phase is the e-negotiation phase, in which stakeholders make their proposals and the computer system provides suggestions to improve them. To simulate real-world negotiations where stakeholders make proposals and counterproposals in a series of negotiation rounds, we implemented the Indifference Curve approach to enable stakeholders to make incremental changes of their proposals during negotiation. The results from our experiment suggest that our method can produce an optimum solution for a multi-issue and multi-stakeholder decision problem by moving stakeholders' proposals closer to one another.
\end{abstract}

Keywords: Stakeholders, Negotiation, Computer, Mediation 


\section{Introduction}

During the last three decades, we can observe a significant shift from Top-Down Planning to Bottom-Up Planning (Lane, 2005; UN-Habitat, 2009; Mohammadi, 2010; Crescenzi and Rodriguez-Pose, 2011; Smith, 2014) as the result of a global effort to increase the involvement of stakeholders in public decision-making, partly in response to deteriorating financial positions of governments, due to successive economic crises. In top-down planning processes, politicians with the assistance of bureaucrats and planning experts formulate final planning proposals. Although the results of top-down planning processes are mostly accessible through public libraries or government offices' websites, the process is lacking transparency due to limited involvement of stakeholders during the analysis and decision-making phases (van der Windt, Swart and Keulartz, 2007). The implementation of top-down planning is often supported more by regulations, with a clear penalty for those who disregard it, rather than by stakeholders. In contrast to a top-down planning where stakeholders are only involved in the implementation of the decision, a bottom-up planning process may produce a decision that has full support of all stakeholders because stakeholders are also involved in the planning process. Even when some stakeholders are not completely content with the final decision, they acknowledge their differences and find an acceptable solution. Bottom-up planning processes can be further improved when stakeholders can exchange their preferences. However, this may lead to the realization that they have conflicting interests. In such situations, negotiation among stakeholders is required to resolve the conflicts of interests.

Previous efforts to implement bottom-up planning approaches have mainly focused on the "communicative paradigm" (Healey, 1992; Fainstein, 2000; Märker and Pipek, 2000; Allmendinger and Tewdwr-Jones, 2005; Mohammadi, 2010; Hu, de Roo and Lu, 2013), which argues that planning and decision-making processes can be improved when stakeholders are provided with a means to communicate their opinions to planners (Innes, 1998; Appleton and Lovett, 2005; Simeonova and van der Valk, 2016). The most common method of stakeholders' involvement in communicative bottom-up planning practices is by inviting them in public meetings where they can interact with supra decision makers such as government and planners to speak out their preferences towards issues of decision-making. Despite the significant improvement of stakeholders' involvement when a communicative paradigm is implemented in bottomup planning, some adjustments are still required (Fischler, 2000; Martens, 2001; Sutriadi and Wulandari, 2014). The main drawback of the communicative paradigm is that it is not focused on supporting stakeholders to communicate their differences and adjust their preferences towards decision problems, but rather to gather stakeholders' opinions as much as possible to be evaluated by experts or planners. When stakeholders have conflicting views and interests, their preferences are collected, and then with their expertise and experience, planners make the final decision, sometimes with several public meetings during the decision-making process. During those public meetings, stakeholders are informed about the progress of the planning process, and again, asked about their views. However, stakeholders usually are not allowed to exchange their 
preferences, because planners tend to keep stakeholders' preferences for themselves to avoid conflicts, and only present stakeholders with the results of the planning process.

Even when they are allowed to defend their position, the process only supports the communication of preferences and underlying arguments. Thus, another approach is required to improve stakeholders' participation in planning and decision-making (Ataov, 2007; Khan and Swapan, 2013), because it is important that the stakeholders are capable to communicate to reach an agreement. Even a simple negotiation and mediation support tool can improve urban planning if it successfully helps stakeholders to reach agreement.

As an alternative to the communicative paradigm, we propose a bottom-up planning approach that focuses on negotiation among stakeholders in decision-making. While the concept of negotiation in decision-making itself is not completely new, its implementation in a bottom-up planning process is still very limited compared to the communicative paradigm. The key difference between the communicative paradigm and the negotiation approach is the explicit understanding that the aim of the planning process is to negotiate an outcome that ultimately is explicitly supported by all stakeholders involved.

Considering the relevance of negotiation in modern public private partnership planning processes and the virtual lack of examples of negotiation support systems in urban planning, the goal of our project is to develop a negotiation support system that not only provides a platform of communication but also includes an approach where the computer system can evaluate each stakeholders' proposals and generates alternative proposals that have a higher chance of being accepted by other stakeholders, increasing the efficiency and effectiveness of the negotiation process. In this paper, we show an example of how this system solves a multi-stakeholder, multi-issue decision problem.

To illustrate our negotiation model, a land allocation problem is used as an example of a planning decision problem. The most common method for solving such problem is the combination of Geographic Information Systems (GIS) and Multi-Criteria Decision-Making (MCDM) (Sugumaran and Degroote, 2010). This approach emerged as a Spatial Decision Support System (SDSS), (Arampatzis et al., 2004), which is an interactive, computer-based system that can help stakeholders in planning and decisionmaking by solving semi-structured spatial problems (Malczewski, 2006; Zhang, Li and Fung, 2012). In this approach, criteria are grouped into two categories, factors and constraints. Factors are variables that promote or demote alternatives against decision objectives, weighted according to their relative importance. Constraints are limitations that make some alternatives infeasible (Ascough II et al., 2002; Sánchez-Lozano and Bernal-Conesa, 2017). Then, in GIS, each factor and constraint is represented as a unique map layer, and then a specific aggregation technique is implemented to combine the information of those factors and constraints into Land Suitability Map or Land Allocation Map, which depends on the objective of the MCDM process. It is commonly recognized that this approach tends to be focused more on data and the aggregation of stakeholders' preferences, rather than stakeholders' participation. As the result, plan or 
decision which is formulated using this approach often leads to negative acceptance by stakeholders (Barton, Plume and Parolin, 2005; Zheng et al., 2015).

We try to solve a land allocation problem using a different approach, which is by stakeholders exchanging their proposals until an agreement is reached, using the support of a computer system that acts as a mediator. To enable a computer system mediating the negotiation, a negotiation model is developed, which is an expansion of an existing method, namely the Orthogonal Strategy (Kamps, 2013). Previous works where the orthogonal strategy was implemented in a computer-mediated negotiation use one of the two approaches of how the indifference curves represent stakeholders' utility level. The first approach is only using one indifference curve for each stakeholder. During negotiation, stakeholders moved their proposals along his or her indifference curve until the agreement is reached. In theory, this method indicates that players stay with the same utility level or received the same payoff during negotiation, which is not a correct representation of a negotiation. In real-world negotiations, players mostly are required to adjust their accepted payoff during negotiation so that their proposals can move closer to one another. This process is not represented in implementations of Orthogonal Strategy where only one indifference curve is used. The second approach is to generate a multiple indifference curves for each stakeholder that represent different levels of their utility. This approach allows stakeholders to move from one utility level to another during negotiation.

Implementations of the orthogonal strategy in computer mediated negotiations mostly only using one indifference curve (Gerding, 2004; Wu, Weerdt and Poutre, 2009). In this paper, an improvement to Orthogonal Strategy is introduced, which is the presence of multiple indifference curves for each stakeholder to represent his or her different payoffs towards different bundles of negotiation issues. During negotiation, players may move their proposals from one indifference curve to another to indicate they accept a different level of utility or payoff.

To test whether the negotiation model can solve multi-issue, multi-stakeholder negotiation, we formulate three hypothetical stakeholders with different utility functions. Thus, for each stakeholder, we generate hypothetical preferences toward different bundles of negotiation issues. We also assign a stakeholder's pre-negotiation proposal towards the desired land allocation. Based on the hypothetical preferences/utility functions, indifference curves are calculated for each stakeholder, and an automatic negotiation is conducted by moving stakeholders' proposals from one indifference curve to another to test whether the model can produce an optimal solution.

\section{Negotiation Setting}

There are two types of computer-based negotiations (Kersten and Lai, 2007; Rouhshad, Wigglesworth and Storch, 2015). The first type is computer-supported negotiations, where stakeholders are relying on a computer system to reduce the cognitive efforts required in negotiation, thus expanding stakeholders' ability to assess available alternatives and their possible implications. The main role of computer system in this type of negotiation is to provide stakeholders with information related to negotiation issues, thus providing an easier access toward the values of parameters or indicators 
that are considered in the negotiation. In computer-supported negotiation, while negotiating, stakeholders can look at considerations such as available alternatives, possible consequences, negotiation parameters, and constraints, which are provided by the computer. This type of negotiation requires an exchange of offers among stakeholders as in classical negotiation where stakeholders are engaged in face-to-face negotiation, because the final decision is built upon interactions among stakeholders, not calculated by a computer system. Although direct negotiation offers a better flow of information among the negotiating parties (Galin, Gross and Gosalker, 2007), this type of negotiation often leads to an ineffective outcome (Rangaswamy and Shell, 1997; Wilken, Jacob and Prime, 2013), mainly because only a limited number of stakeholders can be involved in this type of negotiation, to ensure an effective exchange of information among stakeholders. When a relatively large number of stakeholders are involved, the flow of information between them will become inefficient, and some stakeholders will influence the negotiation more than others. An illustration of this type of computer-supported negotiation is shown in Figure 1.

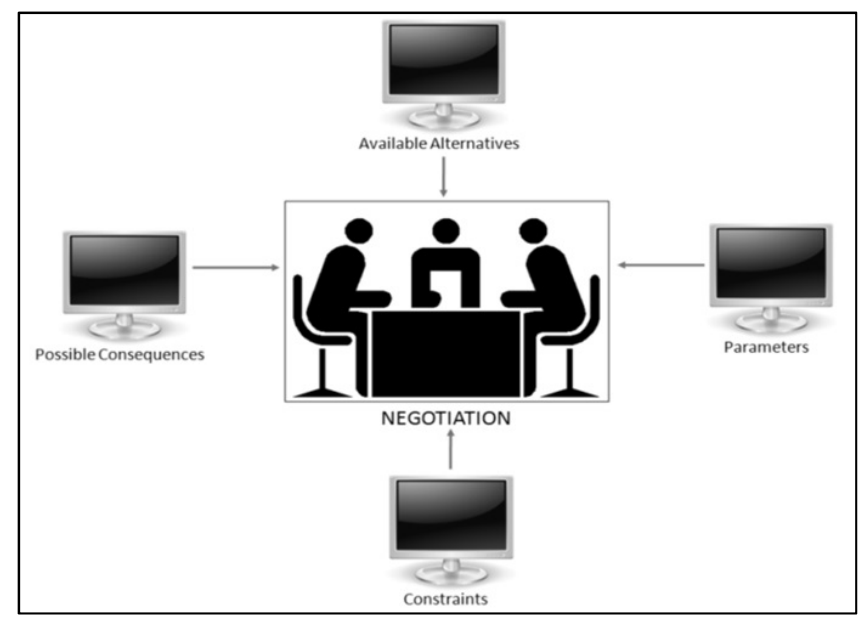

Figure 1. Computer-supported Negotiation

The second type is computer-mediated negotiation or e-negotiation, where stakeholders are not directly engaged in negotiation, but rather mediated by a computer system. The role of the computer systems of this type of negotiation is to identify differences among stakeholders, and make suggestions to reduce any differences. These computer-mediated negotiations may help stakeholders to reach a higher degree of objectivity, because the negotiation issues are separated from how stakeholders view themselves and one another (Carmel, Herniter and Nunamaker, 1993; Zwaard and Bannink, 2016), and a large number of stakeholders can be involved in this type of negotiation. This type of negotiation can be seen in figure 2 . 


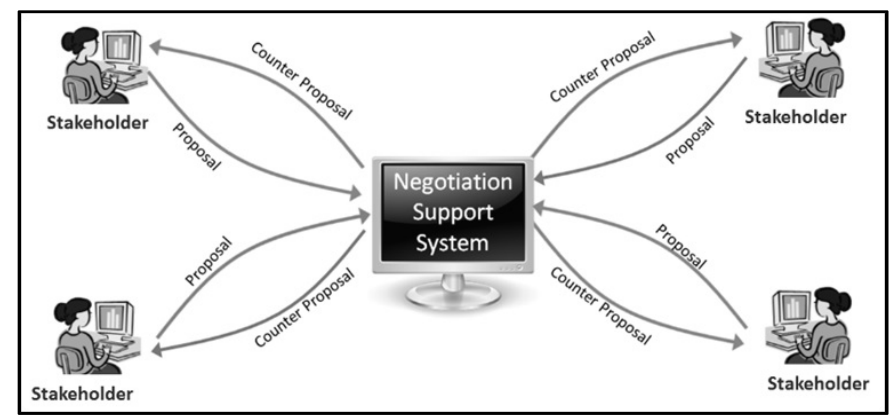

Figure 2. Computer-mediated Negotiation

Figure 2 (Ito and Shintani, 1997; Morge and Beaune, 2004) above shows that stakeholders do not directly interact. Instead, their proposals are submitted to the system, which then produces counter-proposals to reduce the differences among stakeholders' proposals.

In this paper, we discuss an example of a computer-mediated negotiation to improve stakeholders' involvement in planning and decision-making process. The focus of this paper is the Spatial Aspect of planning and decision-making, where implementations of computer systems to improve stakeholders' involvement is the most evident compared to other aspects of planning such as social, economic, and legal-formal aspects. To demonstrate how the computer system can play a role in solving a decision problem in spatial planning, a Land Allocation issue is selected as the negotiation problem. The study area of our experiment is the eastern district of Surabaya City, Indonesia. For this location, the government of Surabaya City imposed a land use plan that will be valid until 2018. However, on-site observations show that new housing developments violated the plan, while they already have the required permits. Hence, there is a need to reformulate the land use allocation in this area to accommodate this new development and prevent the same violation occurring again in the future. Figure 3 shows the land use plan, and the deviation between existing and planned land use.

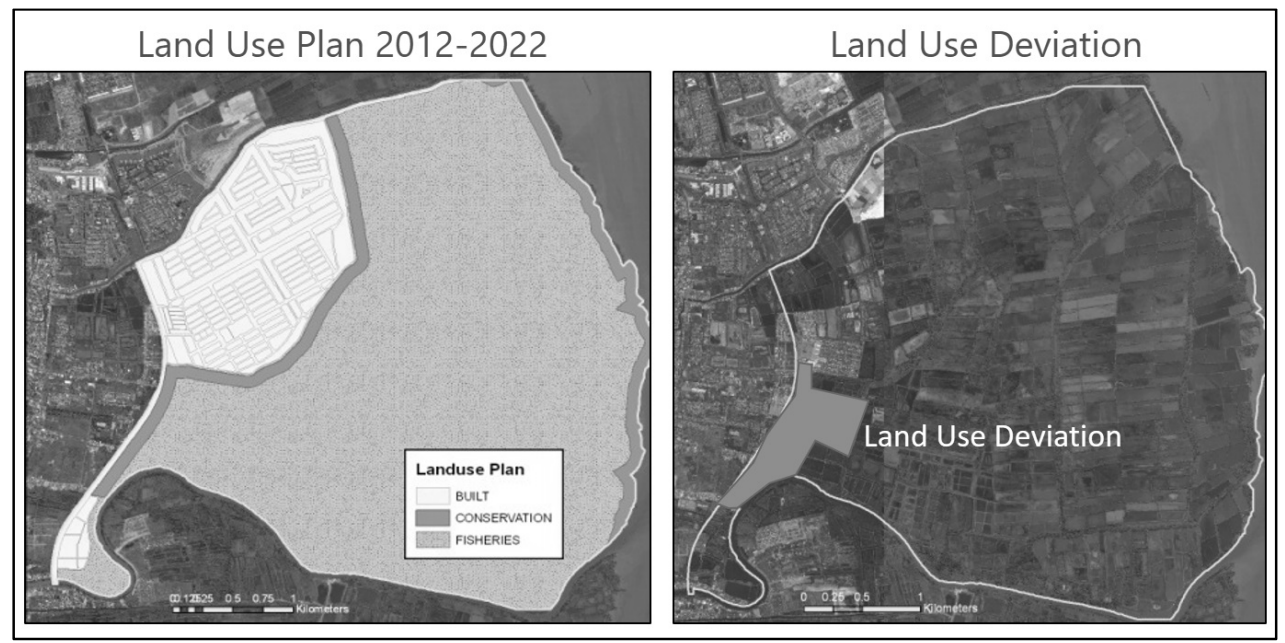

Figure 3. Land use plan and the deviation in the study area 
In this paper, a stakeholders' negotiation approach is implemented to help stakeholders solving a land allocation issue. Instead of using GIS and MCDM, stakeholders were invited to negotiate the new proportion of each land use type to generate a new land use plan. Thus, to enable stakeholders exchanging their proposals in a participatory decision-making process, the new role of planners and decisionmakers is defined as mediator that collect stakeholders' preferences toward negotiation issue, construct them to a mathematical model, and then develop a computer system that can provide suggestions to reduce the difference among stakeholders' proposals. Negotiation Issues in this paper are the allocations of three types of land uses, which are Built-Up, Fisheries, and Conservation. Built-Up area consists of housing, commercial, and other facilities. Fisheries consists of fishpond and shrimp nursery pond, and conservation consists of mangrove forest. The objective of the negotiation is to help stakeholders reach agreement towards allocation of those three land use types. Comparison between planned land use allocation and the existing ones for Built-up, Fisheries, and Conservation in the study area can be seen in Table 1.

Table 1. Negotiation Issues

\begin{tabular}{lccl}
\hline \multicolumn{1}{c}{ Land use } & Planned & Existing & New Plan \\
\hline Built-up & $19 \%$ & $7 \%$ & \\
\cline { 1 - 2 } Fisheries & $75 \%$ & $90 \%$ & Decided by Negotiation \\
\cline { 1 - 3 } Conservation & $6 \%$ & $3 \%$ & \\
\hline
\end{tabular}

Negotiation constraints are based on existing land use and regulations, with the following assumptions:

1. Conservation areas are protected by law, so it is not allowed to change the existing ones into Built-up or Fisheries.

2. It is difficult to change an existing Built-up area into Conservation or Fisheries because it is economically not feasible.

3. Although it is economically profitable to change all Fisheries into Built-up, there is a regulation that forces a proportion of land to be allocated to Fisheries.

In a multi-issue and multi-stakeholder decision-making, one can expect that differences among stakeholders may exist. The final decision should be the result of exchange of preferences and negotiation among stakeholders, not decided by supradecision-makers such as government or planners. Ideally, government and planners are participating in the negotiation process. Thus, government/planners are committed to bring the outcome of the negotiation process to the final, formal approval stage of the planning process. To improve the participatory planning process, the government or planners should recognize this issue, and incorporate the results of stakeholders' negotiation into the formal plan or regulation. Therefore, in a computer-mediated negotiation, the role of planners is shifted from the ones who make the final decision, as we can observe in top-down planning, to the ones who formulate a negotiation platform, inviting stakeholders to participate, managing stakeholders' negotiation, and 
evaluate the results of the negotiation. The overview of negotiation can be seen in Figure 4 below.

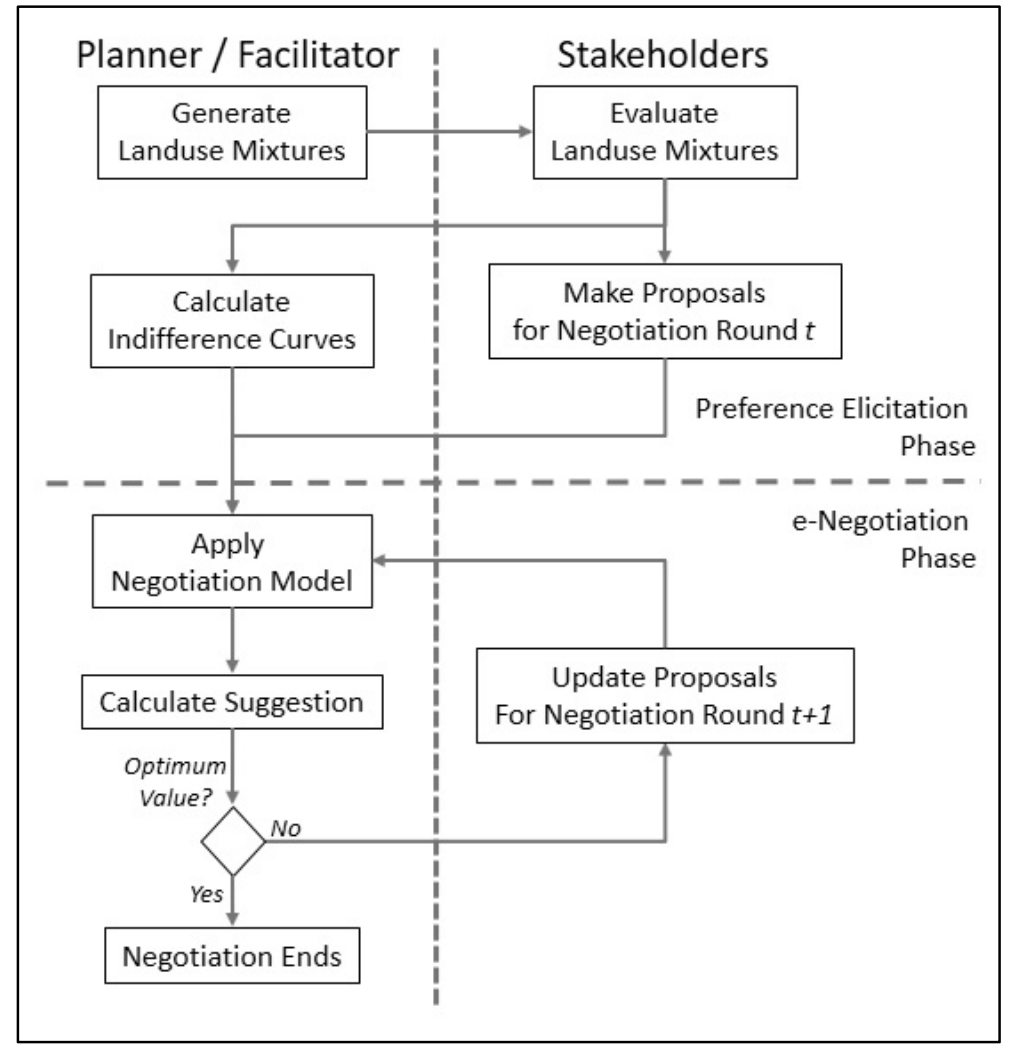

Figure 4. Negotiation Overview

Figure 4 shows the proposed roles of planners and stakeholders in the computermediated negotiation. To enable the computer system to calculate suggestions for stakeholders to improve their proposals, the Orthogonal Strategy is selected as the negotiation model. Orthogonal Strategy works on stakeholders' Indifference Curves, that represent all combinations of two or more negotiation issues that yield an equal payoff for each particular stakeholder (Hall and Lieberman, 2007; Tresch, 2015).

During the preference elicitation phase, planners generate various land use mixtures, which will be evaluated by stakeholders to produce a unique indifference curve for each stakeholder. During the e-negotiation phase, we use Orthogonal Strategy to calculate a suggestion for each stakeholder. When suggestions can move stakeholders' proposals closer, the planner/facilitator will inform these suggestions to stakeholders and asks the value of stakeholders' proposals for the next negotiation round. For each round of negotiation, an Optimal Point is calculated, which is a point that has a minimum average Euclidian distance to all stakeholders' proposals. When the average distance between the optimal point and stakeholders' proposals in a negotiation round is smaller than the previous round, the negotiation continues. On the other hand, when this distance is larger than the previous round, it means that the system cannot produce suggestions that can move stakeholders' proposals closer to one another 
anymore. Therefore, it is considered that the optimum solution is reached, thus the negotiation ends.

\section{Preference Elicitation}

A Computer-Mediated Negotiation requires the computer system to act as a mediator that understands stakeholders' preferences toward negotiation issues. Therefore, a Preference Elicitation is required to enable the system to learn the preferences of stakeholders toward different combinations of negotiation issues. This phase consists of two stages. The first stage of the Preference Elicitation involves stakeholders to complete a mixture experimental design, which is used to measure their preference functions. In this stage, different land allocation scenarios are generated according to the principles of mixture designs, and stakeholders choose their preferred scenarios. In this research, three hypothetical stakeholders are defined, and their judgments are assigned for each of the land-use scenarios, based on assumptions about their preferences toward negotiation issues. For example, we assigned a high utility value for a property developer for land-use scenarios with high proportion of built-up area. On the other hand, for the same land-use scenario, we assigned a low utility value for an environmental activist. The second stage of the Preference Elicitation phase is the specification and estimation of the utility function for each stakeholder. The Independent Variables for this utility function are the proportion of each of the landuse types, while the Dependent Variable is stakeholders' valuation towards the corresponding land-use proportions. Three regression models are utilized to produce utility functions, namely the $1^{\text {st }}$ Degree Polynomial, the $2^{\text {nd }}$ Degree Polynomial, and the Cobb-Douglas Function. Each stakeholder can have a different mathematical model than other stakeholders to represent their preferences toward negotiation issues, depending on which model has the highest accuracy.

\subsection{Mixture Design}

Estimation of multi-attribute utility function are commonly based either on direct sequential evaluation of attribute utility functions or on fractional factorial designs which generate multi-attribute profiles and then solicit value judgments for the generated set of profiles. Land allocation plan differs from this common problem in the sense that the decision is about different percentages of land allocation and the utility related to these different shares. Rather than using fractional factorial designs, this research therefore use Mixture Designs, where discrete lattice points are generated within the decision space in such that the total is equal to 100 percent (Haughton and Haughton, 1996; Kamakura, Kim and Lee, 1996; Morey and Greer Rossmann, 2003; Dane, 2012). In a mixture design approach for preference elicitation, stakeholders state their preferences towards different land-use compositions that can be visualized using a Ternary Plot. The simplest mixture design would be one which points are spread evenly over the ternary plot, namely a "Simplex". A uniform distribution of points in a mixture design is known as "Lattice", and a ternary plot with the degree of the mixture $(\mathrm{m})$, and with number of negotiation issues $(\mathrm{q})$, is referred to as a $\{\mathrm{q}, \mathrm{m}\}$ simplex-lattice 
(Cornell, 2011). The required $P$ pairs of $\{\mathrm{q}, \mathrm{m}\}$ simplex-lattice can be calculated using formula:

$$
P=\frac{(q+m-1) !}{m ! *((q-1)) !}
$$

Where $P$ is the required pairs of mixtures, $q$ is the number of negotiation issues, and $m$ is the Degree of the Mixtures. In this paper, we constructed a $\{3,4\}$ SimplexLattice ternary plot, which according to the formula above requires 15 mixtures. We also consider a minimum accepted allocation as constraints for Built-Up, Fisheries, and Conservation. Then, a ternary plot is generated, as shown in Figure 5 to evaluate the distribution of mixtures, using a method (Smith, 2005), which consists of the following steps;

1. Defining constraints, which are the upper boundary and the lower boundary of the negotiation issues.

2. Drawing straight lines on the Ternary Plot that represent those boundaries.

3. Construction of the Constraint Region that is bounded by boundaries' lines.

4. Construction of a $\{3,4\}$ Simplex Lattice within the Constraint Region, as seen in figure 5 below;

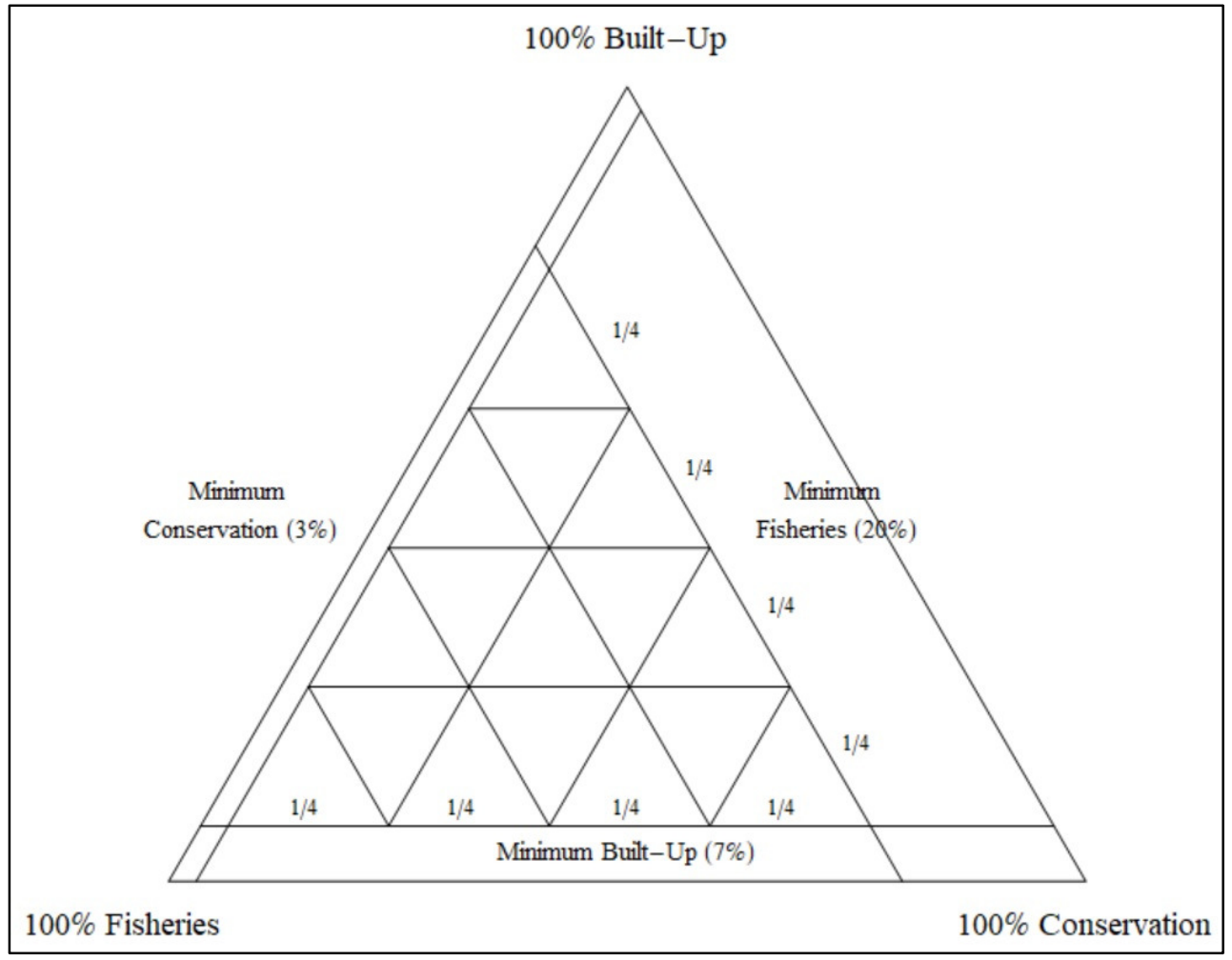

Figure 5. Simplex-Lattice $\{3,4\}$ With Constraints

Based on the distribution of land use mixtures and constraint values, which are Minimum Built-Up Area $=7 \%$, Minimum Fisheries $=20 \%$, and Minimum Conservation $=3 \%$, land use mixtures can be seen in Table 2 . 
Table 2. Land use Mixtures

\begin{tabular}{cccc}
\hline Mixtures & \% Built-up & \% Fisheries & \% Conservation \\
\hline 1 & 7 & 90 & 3 \\
\hline 2 & 7 & 37.5 & 55.5 \\
\hline 3 & 7 & 55 & 38 \\
\hline 4 & 7 & 72.5 & 20.5 \\
\hline 5 & 7 & 20 & 73 \\
\hline 6 & 24.5 & 20 & 55.5 \\
\hline 7 & 42 & 20 & 38 \\
\hline 8 & 59.5 & 20 & 20.5 \\
\hline 9 & 77 & 20 & 3 \\
\hline 10 & 24.5 & 72.5 & 3 \\
\hline 11 & 42 & 55 & 3 \\
\hline 12 & 59.5 & 37.5 & 3 \\
\hline 13 & 42 & 37.5 & 20.5 \\
\hline 14 & 24.5 & 55 & 20.5 \\
\hline 15 & 24.5 & 37.5 & 38
\end{tabular}

To evaluate how negotiation would be implemented in the land allocation problem, three hypothetical stakeholders are used, each with their own unique judgements towards different mixtures of land use according to their objectives in land use allocation. Type of hypothetical stakeholders and their preferences are;

- Stakeholder 1 = "Government", prefers both Built-up and Fisheries equally.

- Stakeholder 2 = "Environmental NGO", prefers Conservation.

- Stakeholder 3 = "Property Developer", prefers Built-Up.

Hypothetical judgements for each stakeholder and each land use mixture are shown in Table 3, with values between 1 (Worst Mixture) to 10 (Best Mixture).

Table 3. Land Use Mixtures with Hypothetical Judgements

\begin{tabular}{cccc}
\hline \multirow{3}{*}{ Mixtures } & \multicolumn{3}{c}{ Hypothetical Judgments } \\
\cline { 2 - 4 } & Stakeholder & Stakeholder & Stakeholder \\
& 1 & 2 & 3 \\
\hline 1 & 8 & 3 & 1 \\
\hline 2 & 6 & 5 & 2 \\
\hline 3 & 5 & 7 & 3 \\
\hline 4 & 3 & 8 & 4 \\
\hline 5 & 1 & 10 & 5 \\
\hline 6 & 3 & 8 & 6 \\
\hline 7 & 5 & 7 & 8 \\
\hline 8 & 6 & 5 & 9 \\
\hline 9 & 9 & 3 & 10 \\
\hline 10 & 9 & 2 & 3 \\
\hline 11 & 10 & 1 & 5 \\
\hline 12 & 10 & 2 & 8 \\
\hline 13 & 8 & 3 & 6 \\
\hline 14 & 8 & 3 & 4 \\
\hline 15 & 5 & 7 & 5 \\
\hline
\end{tabular}




\subsection{Utility Function}

A utility function is a mathematical model of a stakeholder's payoff towards a bundle of negotiation issues (Shao-bin et al., 2007). Based on this utility function, a Utility Curve that shows this stakeholder's preferences in the negotiation can be generated. Then, by using a set of Cut-Off Values, Indifference Curves that represent different utility levels for different land use mixtures (Beattie and LaFrance, 2005; Perloff, 2014) can be generated, as shown in Figure 6 below.

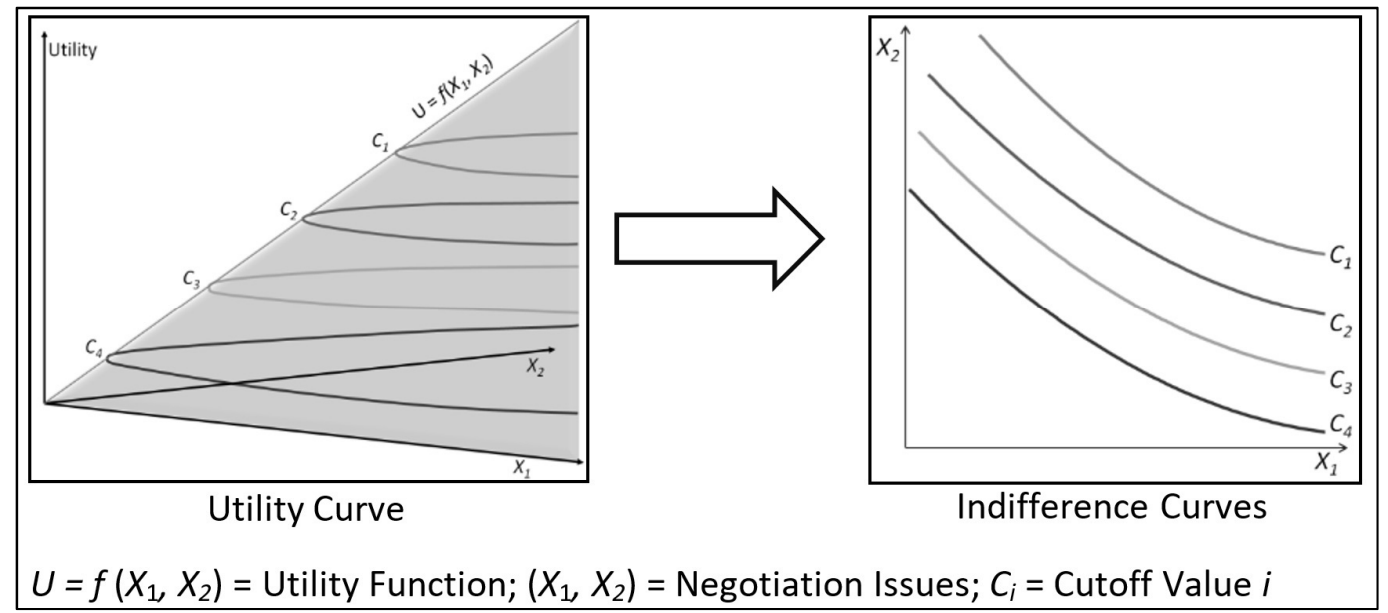

Figure 6. Indifference Curves for Preference Elicitation

Previous works related to Mixture Experiment mostly used Polynomial Regression (Smith, 2005; Althubaiti and Donev, 2011; Cornell, 2011; Dane, 2012; Soares, Quina and Quinta-Ferreira, 2013; Zhang and Wong, 2013). For $1^{\text {st }}$ Degree/Linear Polynomial, the mathematical equation is;

$$
U=\beta_{1} x_{1}+\beta_{2} x_{2}+C
$$

While for $2^{\text {nd }}$ Degree/Quadratic Polynomial;

$$
U=\beta_{1} x_{1}+\beta_{2}\left(x_{1}\right)^{2}+\beta_{3} x_{1} x_{2}+\beta_{4} x_{2}+\beta_{5}\left(x_{2}\right)^{2}+C
$$

Where $U$ is the predicted payoff from the model, $x_{n}$ are the independent variables, $\beta$ is polynomial coefficients, and $C$ is the model's constant. Indifference curves are produced through implementations of polynomial regressions (Somefun et al., 2004; $\mathrm{Wu}$, Weerdt and Poutre, 2009). Another method to generate indifference curves is the Cobb-Douglas Function (Byrns and Stone, 1982; Train, 2003; Pavelescu, 2014), using the following formula:

$$
U=\beta *\left(\left(x_{1}\right)^{\alpha} *\left(x_{2}\right)^{(\alpha-1)}\right)+C
$$

Where $U$ is the predicted utility from the model, $x_{n}$ are the independent variables, $\beta$ is polynomial coefficients, and $C$ is the model's constant. Both polynomial and Cobb- 
Douglas regression produce indifference curves by following the procedure described in Figure 6 above. First, utility curves are generated by each regression, and then, using a set of pre-defined cut-off values, indifference curves are generated. In a substitutive three-attribute mixture where the sum of the mixtures always has a same value (i.e. added up to $100 \%$ ), only two attributes are required to calculate the utility function. The values of the third attribute are dependent to the values of the two other attributes, thus can be omitted from the utility function.

In this paper, only the allocation of Built-up areas $\left(x_{1}\right)$ and Fisheries $\left(x_{2}\right)$ are used. The allocation of Conservation $\left(x_{3}\right)$, is dependent to the values of the two former attributes to sum the land allocation to $100 \%$. Based on Hypothetical judgments as shown in Table 4, three utility functions are generated using Least Square Fitting method, which minimises the difference between the observed values and the predicted values by the model (Rawlings, Pantula and Dickey, 1998; Martin-Fernandez, 2004; Bates and Watts, 2007), and the results are shown in table 4 below.

Table 4. Parameters' Values

\begin{tabular}{|c|c|c|c|}
\hline Estimation Results & Stakeholder 1 & Stakeholder 2 & Stakeholder 3 \\
\hline \multicolumn{4}{|c|}{$1^{\text {st }}$ Degree Polynomial: $U=a+b x_{1}+c x_{2}$} \\
\hline \multicolumn{4}{|c|}{ Parameter Values } \\
\hline$a$ & -1.0498 & 12.3265 & 4.94122 \\
\hline$b$ & 0.112653 & -0.106122 & 0.0783673 \\
\hline$c$ & 0.0930612 & -0.0963265 & -0.0473469 \\
\hline Goodness of Fit $\left(R^{2}\right)$ & 0.73539 & 0.702668 & 0.910313 \\
\hline \multicolumn{4}{|c|}{$2^{\text {nd }}$ Degree Polynomial: $U=a x_{1}+b\left(x_{1}\right)^{2}+c x_{1} x_{2}+d x_{2}+e\left(x_{2}\right)^{2}$} \\
\hline \multicolumn{4}{|l|}{ Parameter Values } \\
\hline$A$ & -0.00299887 & 0.282583 & 0.242582 \\
\hline$B$ & 0.000624898 & -0.00219639 & -0.00101852 \\
\hline$C$ & 0.00229117 & -0.00694285 & -0.0027188 \\
\hline $\bar{D}$ & 0.0962694 & 0.294105 & 0.10349 \\
\hline $\mathrm{E}$ & -0.000433418 & -0.00252743 & -0.00096507 \\
\hline Goodness of Fit $\left(R^{2}\right)$ & 0.974462 & 0.922908 & 0.980754 \\
\hline \multicolumn{4}{|c|}{ Cobb-Douglas Utility Function: $U=a *\left(\left(x_{1}\right)^{b} *\left(x_{2}\right)^{(1-b)}\right)+c$} \\
\hline \multicolumn{4}{|l|}{ Parameter Values } \\
\hline$a$ & 0.226969 & -0.227436 & 0.0739796 \\
\hline$b$ & 0.428012 & 0.403696 & 1.26157 \\
\hline$c$ & -0.820867 & 12.2478 & 2.81766 \\
\hline Goodness of Fit $\left(R^{2}\right)$ & 0.966066 & 0.946998 & 0.96751 \\
\hline
\end{tabular}

Best Fit Utility Function

Results of parameter estimation for $1^{\text {st }}$ Degree Polynomial, ${ }^{\text {nd }}$ Degree Polynomial, and Cobb-Douglas Function can be seen in Table 5, which shows that no regression model can persistently produce the best Coefficient of Determination $\left(R^{2}\right)$ as the indicator of their accuracy. Based on attribute parameters for each type of regression, 3-D utility curves are generated, shown in Figure 7. 


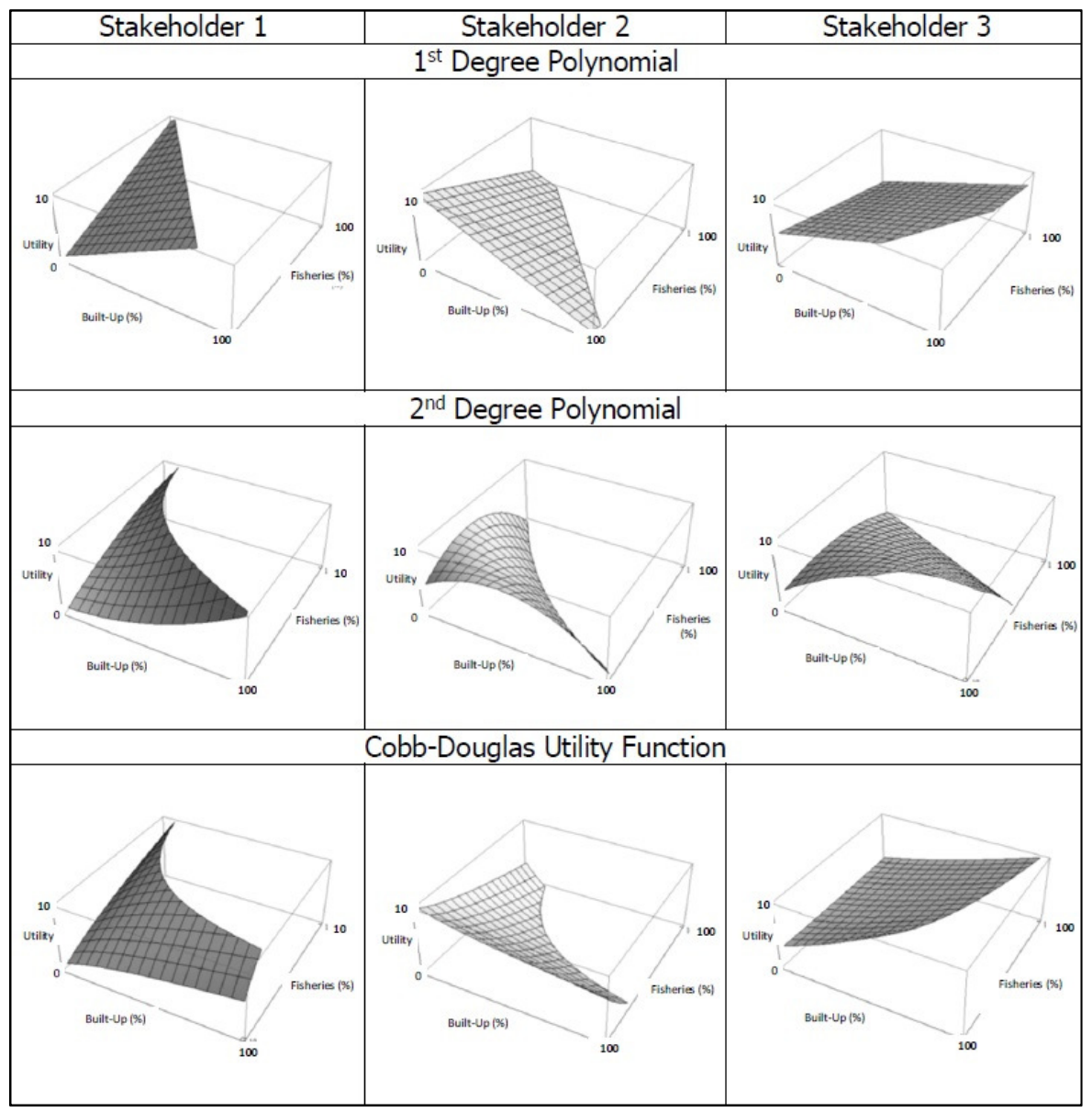

Figure 7. Utility Curves

After Utility Curves are generated, the next step is to calculate indifference curves for each stakeholder using pre-specified cut-off values, as shown in figure 5. Too many cut-off values may lead to a lengthy negotiation because proposals will change only in a small fraction from one negotiation round to the next. Thus, cut-off values are set to 5 values using formula;

$C_{i}=C_{\min }+\left(\left(\frac{\left(C_{\max }-C_{\min }\right)}{(n-1)}\right) *(i-1)\right) ; i, n \geq 1$

Where $n$ indicates how many cut-off values are used, $C_{i}$ is the value of $i^{\text {th }}$ cut-off value, $C_{\max }$ and $C_{\min }$ are maximum and minimum cut-off values respectively. Using this formula, indifference curves for each stakeholder are shown in Figure 8. 


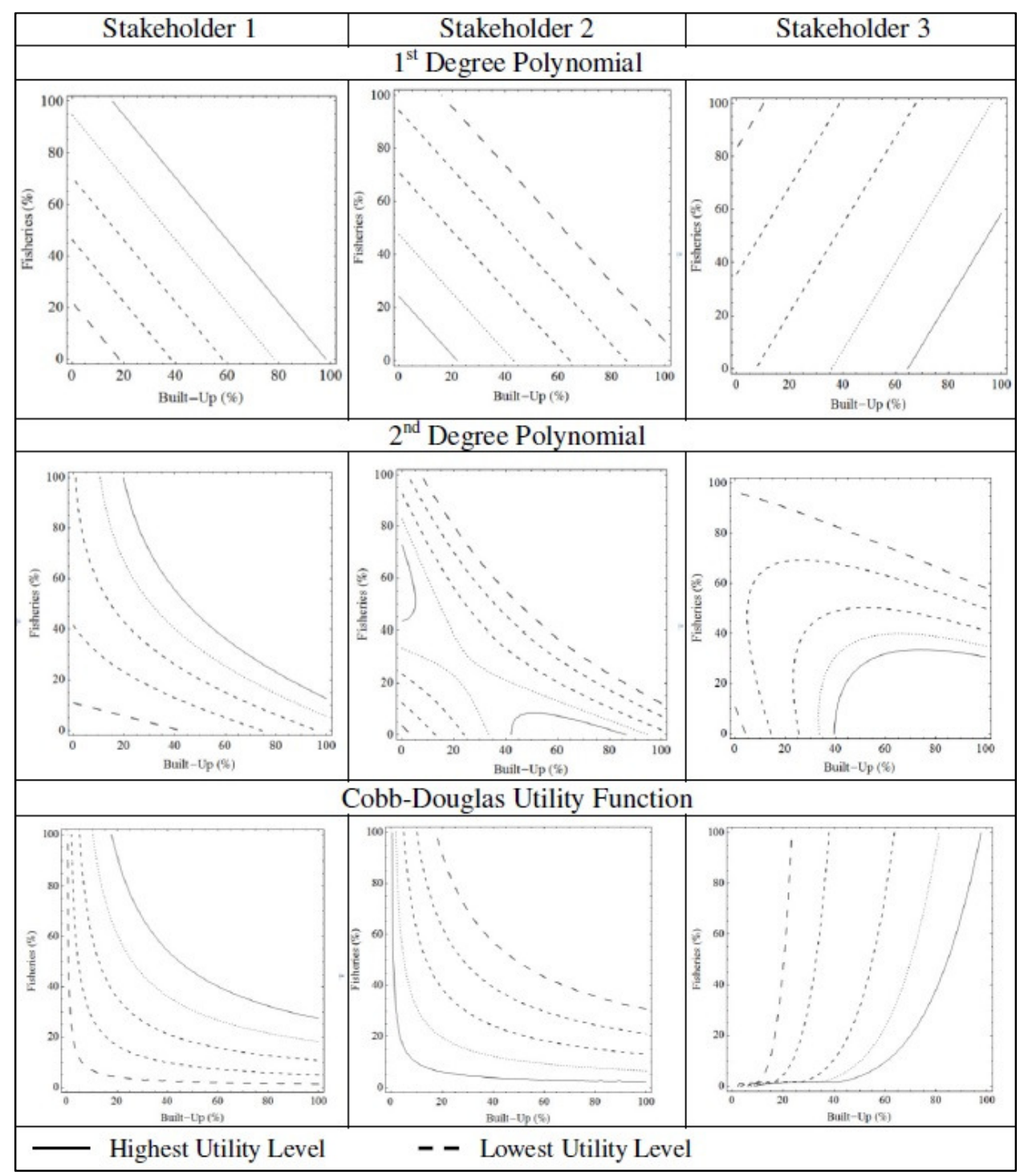

Figure 8. Indifference Curves

\section{Orthogonal Strategy}

Computer-mediated negotiation requires a negotiation model to have a built-in capability to evaluate stakeholders' proposals, and suggest a counter-proposal to enable stakeholders reaching an agreement. For this purpose, we implement Orthogonal Strategy (Wu, Weerdt and Poutre, 2009; Ma et al., 2010; Kamps, 2013). Orthogonal Strategy is a negotiation model which operates on stakeholders' indifference curves (Somefun et al., 2004). Based on all stakeholder's proposal and each indifference curve, Orthogonal Strategy will produce a suggestion for each particular stakeholder. The implementation of Orthogonal Strategy will enable the system to produce suggestions for stakeholders that will move their proposals closer to each other. The basic principle of Orthogonal Strategy in a multi-stakeholder negotiation is that for each stakeholder, the system will give a suggestion to improve his proposal, as a point on one of his indifference curves, which is orthogonal to his reference points, as shown in Figure 9. 


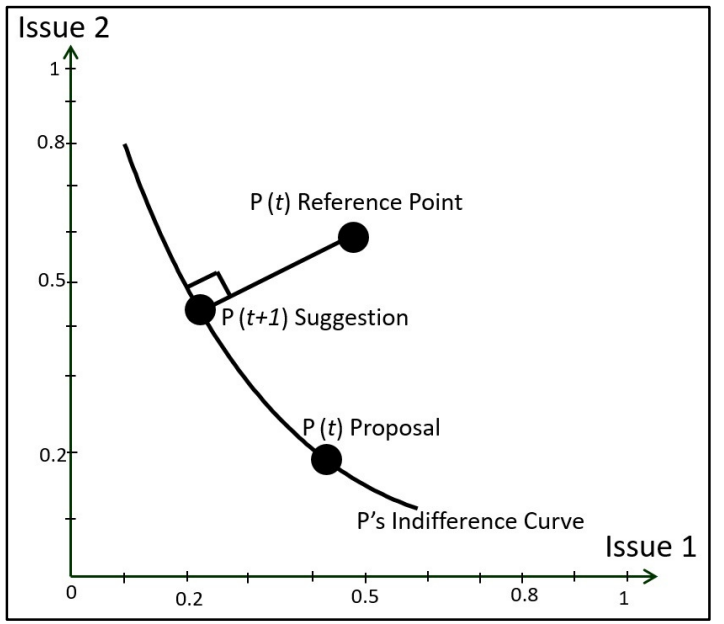

Figure 9. Orthogonal Strategy

The reference point for a particular stakeholder is a point that has the minimum average distance to all other stakeholders' proposals, as seen in Figure 10. For stakeholder $i$ in negotiation round $t$, the computer will calculate his Reference Point $R_{i}$ that consists of a pair of the value of negotiation issues $\left(x_{i}, y_{i}\right)$ based on the proposals of all other stakeholders $j$ that satisfies the following optimization problem (Boyd and Vandenberghe, 2004; Rothlauf, 2011; Korte and Vygen, 2012);

$R\left(x_{i}, y_{i}\right)=\min \frac{\sum_{j=1}^{n} \sqrt{\left(\left(x_{i}-\left|x_{j}\right|\right)^{2}+\left(y_{i}-\left|y_{j}\right|\right)^{2}\right)}}{n} ; i \notin j$

where;

$x_{i}=$ Stakeholder $i$ 's Reference Point for negotiation issue $x$

$y_{i}=$ Stakeholder $i$ 's Reference Point for negotiation issue $y$

$x_{j}=$ Stakeholder $j$ 's proposal for negotiation issue $x$

$y_{j}=$ Stakeholder $j$ 's proposal for negotiation issue $y$

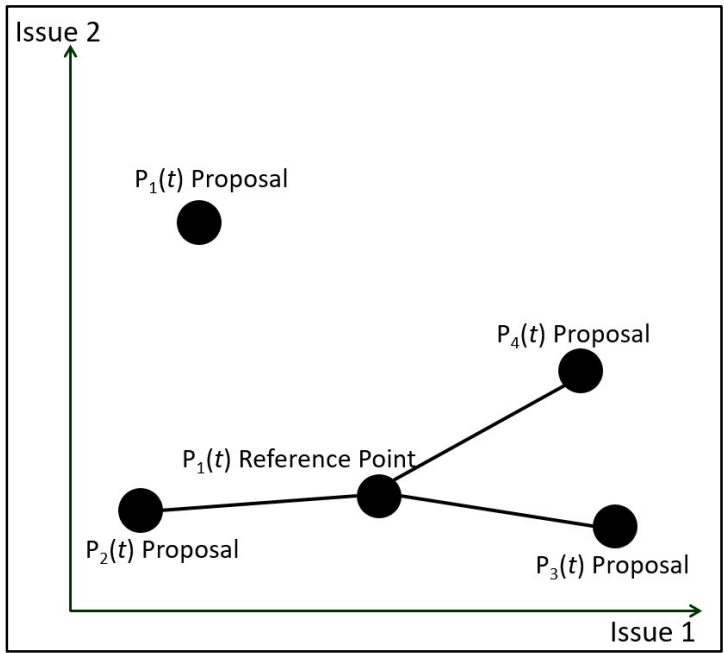

Figure 10. Reference Point Calculation 
If implemented to all stakeholders throughout the entire negotiation process, Orthogonal Strategy enables them to make compromises by moving their proposals closer to one another. For each round of negotiations, an Optimum Point $O(t)$ as shown in Figure 11 is calculated, which is a point that has a minimum distance to all Stakeholder's proposals. For an $n$ number of Stakeholders with negotiation issues $x$ and $y$, the optimum point for each negotiation is defined as a point that consists of a pair of values $x_{O}$ and $y_{O}$ that satisfies the following optimization problem:

$$
O\left(x_{O}, y_{O}\right)=\min \frac{\sum_{i=1}^{n} \sqrt{\left(\left(x_{O}-\left|x_{i}\right|\right)^{2}+\left(y_{O}-\left|y_{i}\right|\right)^{2}\right)}}{n}
$$

where;

$x_{i}=$ Stakeholder $i$ 's Proposal for Negotiation Issue $x$

$y_{i}=$ Stakeholder $i$ 's Proposal for Negotiation Issue $y$

$x_{O}=$ Optimum point's value for Negotiation Issue $x$

$y_{O}=$ Optimum point's value for Negotiation Issue $y$

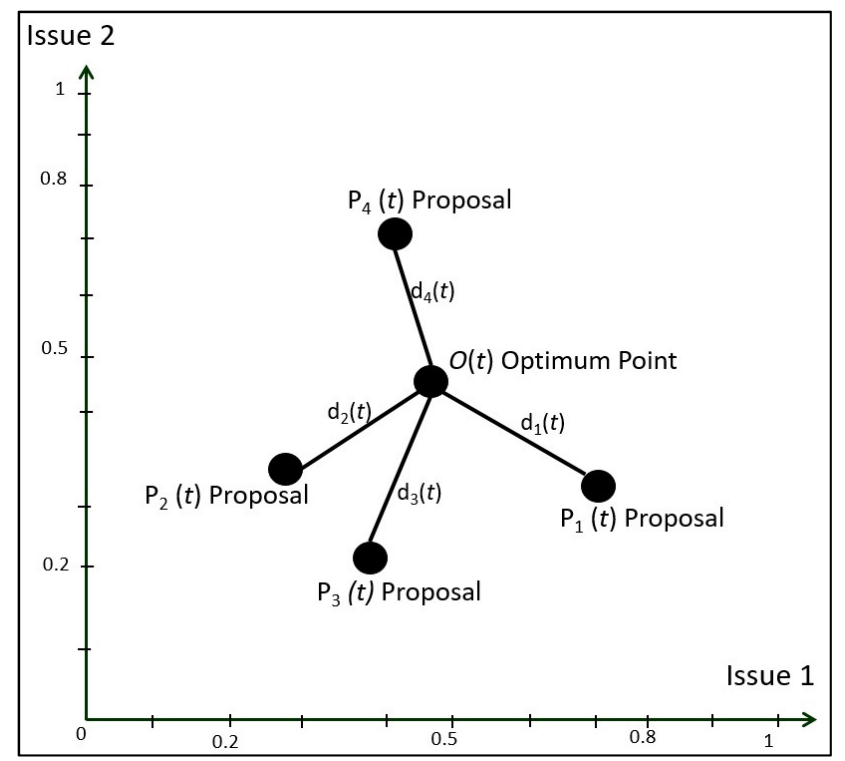

Figure 11. Optimum Point Calculation

In a computer-mediated negotiation, the value of optimum points should not be used as an indicator to decide whether the negotiation shall continue or end. Instead, the Average Value of the distance between the Optimum Point and stakeholders' proposals $\left(d_{i}(t)\right)$ is used to measure the level of convergence achieved during the negotiation. When the average value of $d_{i}(t+1)$ is smaller than the average value of $d_{i}(t)$, the negotiation continues to the next round. Otherwise, the negotiation reaches the optimum solution, thus the negotiation ends. Therefore, the optimum solution is defined as the optimum point during negotiation round $(t)$ when negotiation round $(t+1)$ produces a larger average distance between the optimum point and stakeholders' proposals. 


\section{Computer-Mediated Negotiation}

To test how our model can handle proposals from stakeholders and provide suggestions for them, we conducted a computer-mediated negotiation based on the previously described decision problem. Each stakeholder in negotiation round $(t)$, made a proposal. Using Orthogonal Strategy, a suggestion for each stakeholder is calculated, thus used as a proposal for negotiation round $(t+1)$. An example of this procedure, for Negotiation Round 0 , is shown in Table 5.

Table 5. Negotiation Round 0

\begin{tabular}{|c|c|c|c|c|c|c|c|}
\hline \multirow[t]{2}{*}{ Stakeholder } & \multicolumn{2}{|c|}{ Proposal } & \multicolumn{2}{|c|}{$\begin{array}{l}\text { Reference } \\
\text { Point }\end{array}$} & \multicolumn{2}{|c|}{ Suggestion } & \multirow{2}{*}{$\begin{array}{c}\text { Utility } \\
\text { Compromise }\end{array}$} \\
\hline & $\mathrm{X}$ & $\mathrm{Y}$ & $\mathrm{X}$ & $\mathrm{Y}$ & $\mathrm{X}$ & $\mathrm{Y}$ & \\
\hline Stakeholder 1 & 60 & 36 & 24 & 20 & 24 & 21 & 3-Level Lower \\
\hline Stakeholder 2 & 4 & 18 & 61 & 31 & 63 & 29 & 3-Level Lower \\
\hline Stakeholder 3 & 64 & 16 & 20 & 23 & 23 & 23 & 2-Level Lower \\
\hline
\end{tabular}

$\mathrm{X}=$ Allocation for Built-Up Area, Y = Allocation for Fisheries

The results of the negotiation that we conducted in our experiment can be seen in Table 6, which shows the optimum point for each negotiation round. The average distance between the optimum point and stakeholders' proposals is also calculated to indicate the degree of convergence of the negotiation.

Table 6. Negotiation Summary

\begin{tabular}{|c|c|c|c|}
\hline \multirow{2}{*}{$\begin{array}{l}\text { Negotiation } \\
\text { Rounds }\end{array}$} & \multicolumn{2}{|c|}{ Optimum Point } & \multirow{2}{*}{$\begin{array}{c}\text { Average Distance Between } \\
\text { Optimum Point and Proposals }(\%\end{array}$} \\
\hline & Built-Up (\%) & Fisheries $(\%)$ & \\
\hline Round 0 & 56.1 & 25.9 & 25.4 \\
\hline Round 1 & 33.4 & 20.5 & 15.9 \\
\hline Round 2 & 41.1 & 25.4 & 4.45 \\
\hline Round 3 & 42.2 & 24.3 & 2.77 \\
\hline Round 4 & 43.2 & 24.2 & 1.48 \\
\hline Round 5 & 42.9 & 23.8 & $0.64 *$ \\
\hline Round 6 & 40.5 & 22.1 & 1.6 \\
\hline
\end{tabular}

*Optimum Solution

Because stakeholders' proposals are updated, their utility levels also change. Before negotiation, stakeholders' proposals gave them the highest utility level. During negotiation, their proposals were moving from one indifference curve to another, which also changed their utility level, as shown in Table 7.

Table 7. Utility Compromises

\begin{tabular}{ccc}
\hline \multirow{2}{*}{ Participant } & \multicolumn{2}{c}{ Utility Level } \\
\cline { 2 - 3 } & Before Negotiation & After Negotiation \\
\hline Stakeholder 1 & 10 & 5.41 \\
\hline Stakeholder 2 & 10 & 5.38 \\
\hline Stakeholder 3 & 10 & 7.67 \\
\hline
\end{tabular}




\section{Sensitivity Analysis}

When implementing a computer-mediated negotiation to solve a decision problem, two parameters can be adjusted by a supra-decision-maker who set up the negotiation. The first one is stakeholders' importance during negotiation, and the second one is the number of cut-off values for each stakeholder's indifference curves. In this section, the sensitivity of our negotiation model towards changes of those two negotiation parameters is discussed.

\subsection{Stakeholders' Importance}

In real-world negotiations, stakeholders may have various degrees of importance that will influence the results of the negotiation. In this case, we consider that the more important a stakeholder is, the closer the decision should be to his proposal. Therefore, we represent stakeholders' importance by assigning a weight for each stakeholder during the calculation of the Optimum Point. The optimum point with the weights assigned to stakeholders consists of a pair $x_{O}$ and $y_{O}$ that satisfies the optimization problem:

$O\left(x_{O}, y_{O}\right)=\min \frac{\sum_{i=1}^{n} \sqrt{\omega_{i} *\left(\left(x_{O}-\left|x_{i}\right|\right)^{2}+\left(y_{O}-\left|y_{i}\right|\right)^{2}\right)}}{n} ; \Sigma \omega_{i}=1$

where;

$x_{i}=$ Stakeholder $i$ 's Proposal for Negotiation Issue $x$

$y_{i}=$ Stakeholder $i$ 's Proposal for Negotiation Issue $y$

$x_{O}=$ Optimum point's value for Negotiation Issue $x$

$y_{O}=$ Optimum point's value for Negotiation Issue $y$

$\omega_{i}=$ Weight for Player $i$

To evaluate the negotiation model's sensitivity towards stakeholders' influence during negotiation, we conducted other rounds of negotiation, but this time with different weights for each stakeholder. The weighting schemes were designed by assuming that a stakeholder has a higher or lower importance compared to other stakeholders, as shown in Table 8.

Table 8. Negotiation with Stakeholders' Weight

\begin{tabular}{cccc}
\hline Weighting & \multicolumn{3}{c}{ Weights } \\
\cline { 2 - 4 } Scheme & Stakeholder 1 & Stakeholder 2 & Stakeholder 3 \\
\hline 1 & 0.5 & 0.25 & 0.25 \\
\hline 2 & 0.2 & 0.4 & 0.4 \\
\hline 3 & 0.25 & 0.5 & 0.25 \\
\hline 4 & 0.4 & 0.2 & 0.4 \\
\hline
\end{tabular}

By assigning different weights to each stakeholder, optimum points of negotiation rounds will be located closer or further away from a stakeholder with a higher or lower weight respectively. Comparisons between negotiation with and without stakeholders' weighting can be seen in Figure 12. In the negotiation without weighting, the optimum 
solution was achieved in the fifth round of negotiation. One the other hand, with stakeholders' weighting, the required number of rounds for the negotiation to achieve the optimum solution was reduced.

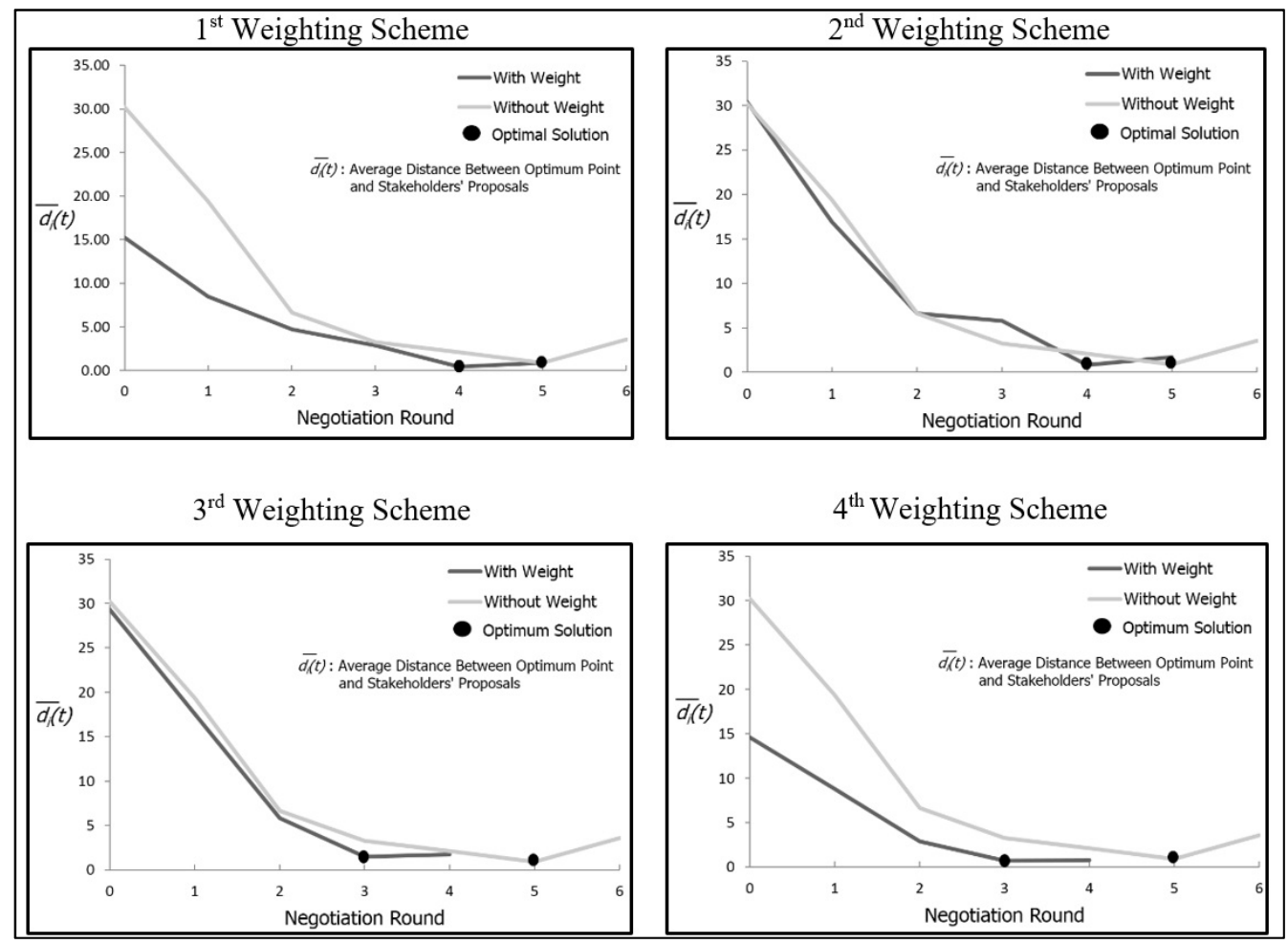

Figure 12. Optimum Points with Stakeholders' Weight

Weight assignment resulted in the improvement of the negotiation process, both by reducing the required negotiation rounds and the differences between stakeholders' proposals and the final decision. However, from a participatory planning's point of view, the level of participation may become compromised because some stakeholders have higher influences towards the final decision compared to others.

\subsection{Cut-off Values}

Another negotiation parameter that may be adjusted by planners is the number of cutoff values for stakeholders' indifference curves. In previous experiments, each stakeholder has five levels of indifference curves. This time instead of five levels, each stakeholder is assigned four cut-off values to represent their different payoff levels. Comparisons between negotiation with five cut-off values and four cut-off values can be seen in Figure 13. In both negotiations, the optimum solution was achieved in the sixth round of negotiation. Therefore, reducing the number of cut-off values has no impact on the required iterations to reach the optimum solution. 


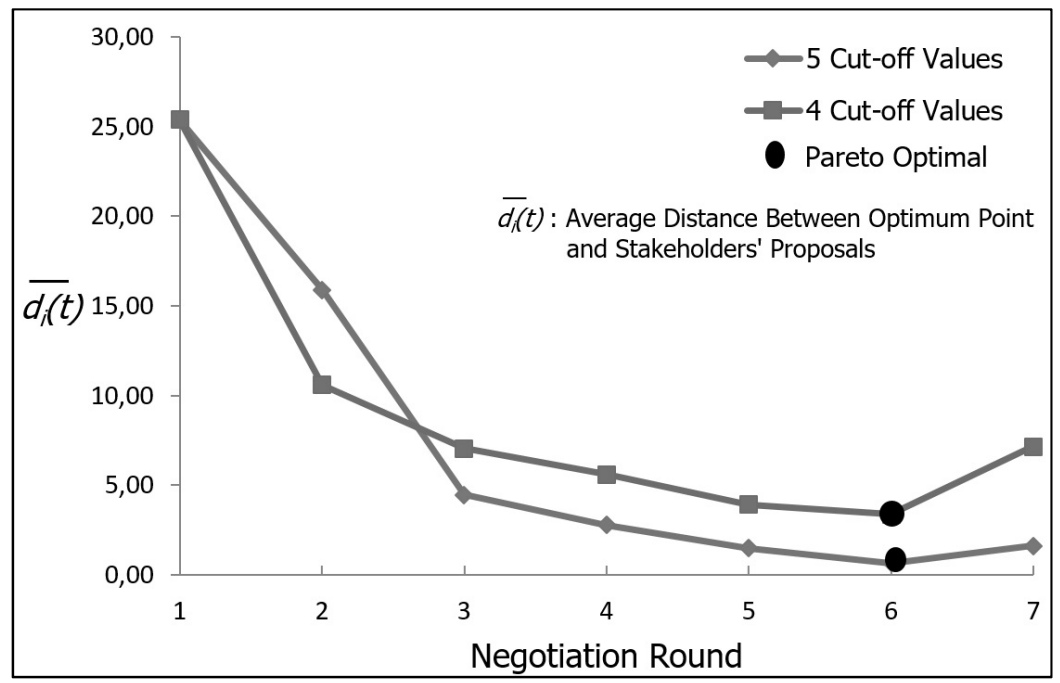

Figure 13. Optimum Points with Different Cut-off Values

Reducing the number of cut-offs from five to four did not change the required number of iterations. On the other hand, it worsens the results of the negotiation, because the differences between Optimum Point and stakeholders' proposals are increased. Therefore, as a rule-of-thumb, the more cut-off values being used, the better the result of negotiation will be. However, too many cut-off values might result in a lengthy negotiation that does not fit the time provided for the negotiation.

\section{Conclusions}

In this paper, we discuss how a computer-mediated negotiation system is implemented to produce a solution in multi-issue, multi-stakeholder decision-making by moving stakeholders' proposals closer to one another in a series of iterations until an optimum solution is reached. We argue this approach can be used as an alternative method to the existing ones to increase the involvement of stakeholders in planning and decisionmaking. The main advantage of our method is that stakeholders have the opportunity to update their proposals during negotiation, either by accepting suggestions or by using their own new proposals.

Compared to the common negotiation methods where stakeholders are directly involved, our method requires an additional pre-negotiation phase, which is the preference elicitation. This is an inherent requirement when developing a computermediated negotiation, because the system needs to learn the preferences of stakeholders to be able to give them suggestions. The result of this step is the capability of the system to recognize stakeholders' attitude towards negotiation issues, thus offering suggestions accordingly.

Orthogonal Strategy is proven a useful model to search for the optimum solution. In theory, continuous negotiation rounds may occur, in the sense that the system is unable to find a solution after extensive iterations. In this case, other indicators can be used as the deciding factor to conclude the negotiation, such as the available time and maximum allowed number of negotiation rounds. Results from the sensitivity analysis show that assigning higher importance to one or more stakeholders may improve the 
results of the negotiation, but from the point of view of participatory planning, the level of participation may be compromised.

In this paper, the objective of the negotiation is to move stakeholders' proposals closer to each other as much as possible, until the optimum solution is reached. However, at this point, despite the minimized differences, the changes in stakeholders' utility is not necessarily on the same level. Some may consider this to be the main drawback of our approach, which focuses on reducing the differences among stakeholders' proposals. On the other hand, the condition is also rarely met in reality.

Since the stakeholders, preferences, and proposals in this paper are hypothetical ones, it is irrelevant to analyse stakeholders' acceptance towards our proposed approach and the applicability of our method here. Therefore, for our future work, we are planning involve real stakeholders. With the involvement of real stakeholders in computer-mediated negotiation, empirical evidence about the applicability of the method can be assessed. Furthermore, stakeholders' acceptance toward computermediated negotiation can be evaluated, and we can get insight into the trust issue that stakeholders may have toward a non-direct interaction among themselves.

\section{Acknowledgement}

The research presented in this paper is supported by Directorate General of Higher Education (DIKTI) - Government of Indonesia, in cooperation with Urban Science and Systems (USS) Group - Eindhoven University of Technology (TU/e)

\section{References}

Allmendinger, P. and Tewdwr-Jones, M. (2005) Planning Futures: New Directions for Planning Theory. Taylor \& Francis.

Althubaiti, A. and Donev, A. N. (2011) 'Mixture experiments with mixing errors', Journal of Statistical Planning and Inference, 141(2), pp. 692-700. doi: 10.1016/j.jspi.2010.07.016.

Appleton, K. and Lovett, A. (2005) 'GIS-based visualisation of development proposals: reactions from planning and related professionals', Computers, Environment and

Urban Systems, 29(3), pp. 321-339. Available at: http://www.sciencedirect.com/science/article/B6V9K-4D4D0X51/2/5f22c9ab90d455d8edd8d313ba9def55.

Arampatzis, G. et al. (2004) 'A GIS-based decision support system for planning urban transportation policies', European Journal of Operational Research, 152(2), pp. 465-475. doi: Doi: 10.1016/s0377-2217(03)00037-7.

Ascough II, J. C. et al. (2002) 'Multicriteria spatial decision support systems: overview, applications, and future research directions.', Online Proceedings of the International Environmental Modelling and Software Society Conference on Integrated Assessment and Decision Support, 3. Available at: http://www.iemss.org/iemss2002/.

Ataov, A. (2007) 'Democracy to become reality: Participatory planning through action research', Habitat International, In Press,. Available at: 
http://www.sciencedirect.com/science/article/B6V9H-4NWN2YN-

1/2/d234e5bb63cc4d2f9034467c71bb3ba1.

Barton, J., Plume, J. and Parolin, B. (2005) 'Public participation in a spatial decision support system for public housing', Computers, Environment and Urban Systems, 29(6), pp. 630-652. Available at: http://www.sciencedirect.com/science/article/B6V9K-4H877802/2/bd54047eae496bfb235fc2540c5f5927.

Bates, D. M. and Watts, D. G. (2007) Nonlinear regression analysis and its applications. John Wiley \& Sons (Wiley series in probability and statistics. Probability and statistics section).

Beattie, B. R. and LaFrance, J. T. (2005) The law of demand versus diminishing marginal utility. University of California at Berkeley, Department of Agricultural and Resource Economics and Policy. Available at: http://ssrn.com/abstract $=468200$.

Boyd, S. P. and Vandenberghe, L. (2004) Convex Optimization. Cambridge University Press (Berichte über verteilte messysteme).

Byrns, R. T. and Stone, G. W. (1982) Microeconomics. Scott, Foresman.

Carmel, E., Herniter, B. C. and Nunamaker, J. F. (1993) 'Labor-management contract negotiations in an electronic meeting room: A case study', Group Decision and Negotiation. Springer Netherlands, 2(1), pp. 27-60. doi: 10.1007/bf01384402.

Cornell, J. A. (2011) A Primer on Experiments with Mixtures. Wiley (Wiley Series in Probability and Statistics).

Crescenzi, R. and Rodriguez-Pose, A. (2011) 'Reconciling top-down and bottom-up development policies', Environment and Planning A. Pion Ltd, 43(4), pp. 773780. Available at: http://www.envplan.com/abstract.cgi?id=a43492.

Dane, G. Z. (2012) 'Individuals' activity preferences under time and monetary budget constraints : a mixture amount experiment application', Proceedings of the European Institute of Retailing and Services Studies Conference, 912 July, 2012, Vienna, Austria, p. 9.

Fainstein, S. S. (2000) 'New Directions in Planning Theory', Urban Affairs Review, 35(4), pp. 451-478. doi: 10.1177/107808740003500401.

Fischler, R. (2000) 'Communicative Planning Theory: A Foucauldian Assessment', Journal of Planning Education and Research, 19(4), pp. 358-368. doi: 10.1177/0739456x0001900405.

Galin, A., Gross, M. and Gosalker, G. (2007) 'E-negotiation versus face-to-face negotiation what has changed - if anything?', Computers in Human Behavior, 23(1), pp. 787-797. doi: 10.1016/j.chb.2004.11.009.

Gerding, E. H. (2004) 'Autonomous agents in bargaining games: an evolutionary investigation of fundamentals, strategies, and business applications'. Technische Universiteit Eindhoven. Available at: citeulike-article-id:8486039.

Hall, R. and Lieberman, M. (2007) Microeconomics: Principles and Applications. Cengage Learning (Available Titles CengageNOW Series).

Haughton, D. and Haughton, J. (1996) 'Using a mixture model to detect son preference in Vietnam', Journal of Biosocial Science, 28(3), pp. 355-365. 
Healey, P. (1992) 'Planning through debate: the communicative turn in planning theory', Town Planning Review, 63(2), p. 143. Available at: http://liverpool.metapress.com/content/422X602303814821.

$\mathrm{Hu}, \mathrm{Y}$., de Roo, G. and Lu, B. (2013) “Communicative turn” in Chinese spatial planning? Exploring possibilities in Chinese contexts', Cities, 35, pp. 42-50. doi: http://dx.doi.org/10.1016/j.cities.2013.05.001.

Innes, J. E. (1998) 'Information in Communicative Planning', Journal of the American Planning Association. Routledge, 64(1), pp. 52-63. doi: 10.1080/01944369808975956.

Ito, T. and Shintani, T. (1997) 'Persuasion among Agents: An Approach to Implementing a Group Decision Support System Based on Multi-Agent Negotiation', in In Proceedings of the 5th International Joint Conference on Artificial Intelligence (IJCAI). Morgan Kaufmann, pp. 592-597.

Kamakura, W. A., Kim, B.-D. and Lee, J. (1996) 'Modeling Preference and Structural Heterogeneity in Consumer Choice', Marketing Science. INFORMS, 15(2), pp. 152-172. doi: 10.1287/mksc.15.2.152.

Kamps, S. (2013) Dual-agent simulation model of the residential development process: an institutional approach to explaining the spatial patterns of residential developments in France, England and the Netherlands. Universite de FrancheComte.

Kersten, G. and Lai, H. (2007) 'Negotiation Support and E-negotiation Systems: An Overview', Group Decision and Negotiation. Springer Netherlands, 16(6), pp. 553-586. doi: 10.1007/s10726-007-9095-5.

Khan, S. and Swapan, M. S. H. (2013) 'From blueprint master plans to democratic planning in South Asian cities: Pursuing good governance agenda against prevalent patron-client networks', Habitat International, 38, pp. 183-191. doi: http://dx.doi.org/10.1016/j.habitatint.2012.06.005.

Korte, B. and Vygen, J. (2012) Combinatorial Optimization: Theory and Algorithms. Springer Berlin Heidelberg (Algorithms and Combinatorics).

Lane, M. B. (2005) 'Public Participation in Planning: an intellectual history', Australian Geographer. Routledge, 36(3), pp. 283-299. doi: 10.1080/00049180500325694.

Ma, H. et al. (2010) 'Multi-player multi-issue negotiation with incomplete information in agent-based activity-travel scheduling', in Proceedings of the 10th Design and Decision Support Systems in Architecture and Urban Planning Conference (DDSS'10), p. 17.

Malczewski, J. (2006) 'GIS-based multicriteria decision analysis: a survey of the literature', International Journal of Geographical Information Science. Taylor \& Francis, 20(7), pp. 703-726. doi: 10.1080/13658810600661508.

Märker, O. and Pipek, V. (2000) 'Computer-Supported Participation in Urban Planning from the viewpoint of "Communicative Planning Theory"', Proc. of IFIP 8.5 Working Conference on Advances in Electronic Government, (Seminario de Informatica y Derecho, Zaragoza, Spain, 2000), IFIP press, pp. 43-58.

Martens, K. (2001) 'Communicative planning and the issue of change.', in Oxford Planning Theory Conference. 
Martin-Fernandez, M. (2004) 'Fundamentals of Estimation Theory'. Available at: http://lmi.bwh.harvard.edu/papers/papers/martin-fernandezCOURSE04b.html.

Mohammadi, H. (2010) Citizen Participation in Urban Planning and Management: The Case of Iran, Shiraz City, Saadi Community. Kassel University Press. Available at: http://www.uni-kassel.de/upress/online/frei/978-3-89958-8842.volltext.frei.pdf.

Morey, E. and Greer Rossmann, K. (2003) 'Using Stated-Preference Questions to Investigate Variations in Willingness to Pay for Preserving Marble Monuments: Classic Heterogeneity, Random Parameters, and Mixture Models', Journal of Cultural Economics. Kluwer Academic Publishers, 27(3-4), pp. 215-229. doi: 10.1023/A:1026365125898.

Morge, M. and Beaune, P. (2004) 'A Negotiation Support System based on a Multiagent System: specificity and preference relations on arguments', Proceedings of the 2004 ACM symposium on Applied computing. Nicosia, Cyprus: ACM, pp. 474-478. doi: 10.1145/967900.967999.

Pavelescu, F. M. (2014) 'Methodological Considerations Regarding the Estimated Returns to Scale in Case of Cobb-douglas Production Function', Procedia Economics and Finance, 8, pp. 535-542. doi: http://dx.doi.org/10.1016/S22125671(14)00125-7.

Perloff, J. M. (2014) Microeconomics. Pearson Education, Limited.

Rangaswamy, A. and Shell, G. R. (1997) 'Using Computers to Realize Joint Gains in Negotiations: Toward an "Electronic Bargaining Table", Management Science. INFORMS, 43(8), pp. 1147-1163. Available at: http://www.jstor.org/stable/2634576.

Rawlings, J. O., Pantula, S. G. and Dickey, D. A. (1998) Applied Regression Analysis: A Research Tool. Wadsworth \& Brooks (Springer Texts in Statistics).

Rothlauf, F. (2011) 'Optimization Problems BT - Design of Modern Heuristics: Principles and Application', in Rothlauf, F. (ed.). Berlin, Heidelberg: Springer Berlin Heidelberg, pp. 7-44. doi: 10.1007/978-3-540-72962-4_2.

Rouhshad, A., Wigglesworth, G. and Storch, N. (2015) 'The nature of negotiations in face-to-face versus computer-mediated communication in pair interactions', Language Teaching Research. SAGE Publications, 20(4), pp. 514-534. doi: $10.1177 / 1362168815584455$.

Sánchez-Lozano, J. M. and Bernal-Conesa, J. A. (2017) 'Environmental management of Natura 2000 network areas through the combination of Geographic Information Systems (GIS) with Multi-Criteria Decision Making (MCDM) methods. Case study in south-eastern Spain', Land Use Policy, 63, pp. 86-97. doi: https://doi.org/10.1016/j.landusepol.2017.01.021.

Shao-bin, D. et al. (2007) 'Preference Elicitation of the NSS in the Ecommerce', Management Science and Engineering, 2007. ICMSE 2007. International Conference on, pp. 135-140. doi: 10.1109/ICMSE.2007.4421837.

Simeonova, V. and van der Valk, A. (2016) 'Environmental policy integration: Towards a communicative approach in integrating nature conservation and urban planning in Bulgaria', Land Use Policy, 57, pp. 80-93. doi: 
http://dx.doi.org/10.1016/j.landusepol.2016.05.017.

Smith, N. R. (2014) 'Beyond top-down/bottom-up: Village transformation on China's urban edge', Cities, 41, pp. 209-220. doi: http://dx.doi.org/10.1016/j.cities.2014.01.006.

Smith, W. F. (2005) Experimental Design for Formulation. Society for Industrial and Applied Mathematics (ASA-SIAM Series on Statistics and Applied Probability).

Soares, M. A. R., Quina, M. J. and Quinta-Ferreira, R. (2013) 'Prediction of free air space in initial composting mixtures by a statistical design approach.', Journal of environmental management, 128, pp. 75-82. doi: 10.1016/j.jenvman.2013.04.041.

Somefun, D. et al. (2004) 'Automated Negotiation and Bundling of Information Goods Agent-Mediated Electronic Commerce V. Designing Mechanisms and Systems', in Faratin, P. et al. (eds). Springer Berlin / Heidelberg, pp. 1-17. doi: 10.1007/978-3-540-25947-3_1.

Sugumaran, R. and Degroote, J. (2010) Spatial Decision Support Systems; Principles and Practices. CRC Press-Taylor\&Francis.

Sutriadi, R. and Wulandari, A. (2014) 'Towards a Communicative City: Enhancing Urban Planning Coordination by the Support of Information and Communication Technology. Case Study Bandung Metropolitan Area, Indonesia', Procedia Social and Behavioral Sciences, 135, pp. 76-81. doi: http://dx.doi.org/10.1016/j.sbspro.2014.07.328.

Train, K. (2003) Discrete Choice Methods With Simulation. Cambridge University Press.

Tresch, R. W. (2015) 'Chapter 2 - A General Equilibrium Model for Public Sector Analysis BT - Public Finance (Third Edition)', in. San Diego: Academic Press, pp. 21-36. doi: https://doi.org/10.1016/B978-0-12-415834-4.00002-9.

UN-Habitat (2009) Planning Sustainable Cities: Global Report on Human Settlements 2009. Earthscan (Global report on human settlements).

Wilken, R., Jacob, F. and Prime, N. (2013) 'The ambiguous role of cultural moderators in intercultural business negotiations', International Business Review, 22(4), pp. 736-753. doi: http://dx.doi.org/10.1016/j.ibusrev.2012.12.001.

van der Windt, H. J., Swart, J. A. A. and Keulartz, J. (2007) 'Nature and landscape planning: Exploring the dynamics of valuation, the case of the Netherlands', Landscape and Urban Planning, 79(3-4), pp. 218-228. doi: 10.1016/j.landurbplan.2006.02.001.

Wu, M., Weerdt, M. and Poutre, H. (2009) 'Efficient Methods for Multi-agent Multiissue Negotiation: Allocating Resources', Proceedings of the 12th International Conference on Principles of Practice in Multi-Agent Systems. Nagoya, Japan: Springer-Verlag, pp. 97-112. doi: 10.1007/978-3-642-11161-7_7.

Zhang, C. and Wong, W. K. (2013) 'Optimal designs for mixture models with amount constraints', Statistics \& Probability Letters, 83(1), pp. 196-202. doi: 10.1016/j.spl.2012.08.029.

Zhang, Y. J., Li, A. J. and Fung, T. (2012) 'Using GIS and Multi-criteria Decision Analysis for Conflict Resolution in Land Use Planning', Procedia Environmental 
Sciences,

13

pp.

$2264-2273$.

doi:

http://dx.doi.org/10.1016/j.proenv.2012.01.215.

Zheng, W. et al. (2015) 'Critical issues in spatial distribution of public housing estates and their implications on urban renewal in Hong Kong', Smart and Sustainable Built Environment. Emerald, 4(2), pp. 172-187. doi: 10.1108/SASBE-09-20140047.

Zwaard, R. van der and Bannink, A. (2016) 'Non-occurrence of Negotiation of Meaning in Task-Based Synchronous Computer-Mediated Communication', The Modern Language Journal, 100(3), pp. 625-640. doi: 10.1111/modl.12341. 